\title{
The salt tolerance of greenhouse crops
}

\author{
C. Sonneveld
}

Glasshouse Crops Research Station, P.O. Box 8, NL 2670 AA Naaldwijk, Netherlands

Received 22 December 1986; accepted 19 August 1987

Key words: greenhouse crops, salinity, salt tolerance

\begin{abstract}
Over a number of years, experiments were carried out to test the salt tolerance of greenhouse crops. The experiments were arranged in such a way that osmotic effects as well as specific salt effects could be assessed. In case of the osmotic effects, salt contents of the irrigation water were increased adding a salt mixture. Specific ion effects of sodium chloride were tested by comparing the addition of this salt with the addition of the salt mixture on the basis of equal EC values. Specific effects of several salts were determined by addition of the salts on the basis of equivalent ion concentrations. The $\mathrm{EC}$ value of the irrigation water in the different experiments varied roughly between 0 and $5 \mathrm{dS} \cdot \mathrm{m}^{-1}$ at $25^{\circ} \mathrm{C}$.

Crop yields were determined as well as quality characteristics of the products harvested. Soil samples were collected and soil salinity was determined by measuring the EC value of the saturation extract. If necessary, specific ions were determined separately. Salinity yield decrease values and salinity threshold values were calculated. It is shown that with respect to the quality of greenhouse crops, salinity may have positive as well as negative effects.
\end{abstract}

\section{Introduction}

Salinity is a world-wide problem which has been studied for many years. In greenhouses, soil salinity is caused by the use of low nutrient fertilizers, by rising water tables, and by the use of saline irrigation water. Salinization of greenhouse soils by fertilization can be avoided by using the proper fertilizers. Salinization by capillary rise of ground water can be prevented by an adequate drainage and irrigation regime. However, salinization by irrigation water still poses a problem. Such is the case in the Netherlands. The greenhouses are situated mainly in the western part of the country. Surface water from the canals and ditches in this region is used for irrigation of the greenhouse crops. The quality of this water is strongly affected by the quality of the water of the river Rhine. The salt content of the Rhine has strongly increased over the past decades, mainly caused by the industrial developments in 
Germany and France. This had a negative influence on the surface water quality in the region.

In order to get information about yield reductions of greenhouse crops caused by saline irrigation water, research was already carried out about 50 years ago. However, results of this classic research were far from adequate to serve as a basis for proper estimations of yield reductions of crops grown under the conditions of modern greenhouse horticulture. Therefore, research on effects of saline irrigation water was started again in the sixties at the Glasshouse Crops Research Station at Naaldwijk. Since then, a great number of crops was tested on salinity effects in several experiments during a period of 20 years. Some results have been published (Sonneveld \& van Beusekom, 1972; Sonneveld \& van den Ende, 1975; Sonneveld \& Voogt, 1978; Sonneveld, 1979; Sonneveld \& Voogt, 1983). In the present paper an overview is given of all data obtained in order to provide a general tool in estimating salt damage of greenhouse crops.

\section{Materials and methods}

\section{Experiments}

Some of the experiments were carried out in the greenhouse border soil in situ and some in well-drained containers filled with border soil. The dimensions of the containers were $0.5 \times 0.5 \times 0.5 \mathrm{~m}$.

The experiments were arranged in such a way that osmotic effects as well as specific salt effects could be assessed. The osmotic effects were studied by adding different quantities of a salt mixture to the irrigation water. The composition of this salt mixture was adjusted to the average salt composition of the surface water in the western part of the Netherlands. This means that about $50 \%$ of the ions consisted of sodium and chloride, and the rest of calcium, magnesium, sulphate and bicarbonate (Sonneveld \& van Beusekom, 1972).

Specific salt effects of sodium chloride were tested by comparing the addition of this salt with the addition of the salt mixture on the basis of equal EC values. Specific effects of several other salts were compared by addition of the salts on the basis of equal ion concentrations.

The following experiments were carried out.

Experiment $A$ included two factors, namely the addition of a salt mixture to the irrigation water and the addition of sodium chloride. The EC value of the water itself was $1.0 \mathrm{dS} \cdot \mathrm{m}^{-1}$ at $25^{\circ} \mathrm{C}$. The salt mixture and sodium chloride were added in two quantities, so that the EC value was increased by 0.9 and $1.8 \mathrm{dS} \cdot \mathrm{m}^{-1}$. Hence the $\mathrm{EC}$ of the irrigation water of the nine treatments in this experiment ranged from 1.0 to 4.6. In a first experiment with cucumber, yield reductions caused by salinity were so great that salt additions in a second experiment were halved. The EC values of the irrigation water then ranged from 1.0 to 2.8 .

Experiment $B$ consisted of six treatments. The EC value of the water itself was 0.1 and the salt mixture was added in such quantities that the EC value of the water irrigated ranged from 0.1 to 1.5 . For one tomato crop the salt addition was increased so that the EC value ranged from 0.1 to 2.8 . 
Experiment $C$ included eight treatments. With six treatments the salinity of the irrigation water was increased by the salt mixture so that the EC value ranged from 0.2 to 3.9. For two treatments a mixture with extra sodium chloride was used (Sonneveld \& Voogt, 1983).

Experiment $D$ was conducted to test specific salt effects. Various salts were added to the irrigation water in two concentrations. The salts were divided into two groups. One group consisted of salts with the same anion but with different cations. The reverse was the case in the second group. The following salts were compared: cation group: $\mathrm{NaCl}, \mathrm{KCl}, \mathrm{CaCl}_{2}$ and $\mathrm{MgCl}_{2}$; anion group: $\mathrm{NaNO}_{3}, \mathrm{NaCl}, \mathrm{Na}_{2} \mathrm{SO}_{4}$ and $\mathrm{NaHCO}_{3}$. The binary salts were added in concentrations of 12.5 and 25 $\mathrm{mmol} \cdot \mathrm{l}^{-1}$ and the tertiary salts in concentrations of 8.33 and $16.67 \mathrm{mmol} \cdot \mathrm{l}^{-1}$, thus giving total ion concentrations of 25 and $50 \mathrm{mmol} \cdot \mathrm{l}^{-1}$ for all salts.

The treatments in the factorial experiment $A$ were duplicated, and those in the experiments B, C and D were laid out in four parallels. Experiments A and B were carried out in greenhouse border soil and experiments $C$ and $D$ in containers. Vegetables as well as flowers were used as test crops. In some cases, especially with flower crops, two cultivars were grown, following a splitplot scheme.

\section{Growing conditions}

All experiments were carried out in greenhouses. If possible, the water was applied by using low-level sprinklers. When such a sprinkler system could not be used, like in lettuce growing, overhead sprinkling was employed. Water was applied according to the crops' requirements and to achieve leaching. The nutritional status of the soil was checked regularly and maintained at a level desirable for the various crops.

\section{Soil testing}

Soil salinity was determined by means of soil samples collected from the top layer to a depth of 0.25 or $0.30 \mathrm{~m}$. After drying, a saturation extract was prepared. The EC of the extract $\left(\mathrm{EC}_{\mathrm{e}}\right)$ was determined. After the development of the 1:2 volume extract method (Sonneveld \& van den Ende, 1971) the salinity was usually determined in this extract. The analytical data were converted to values for the saturation extract (Sonneveld \& van den Ende, 1971; Sonneveld \& Voogt, 1983). The EC of the saturation extract was expressed in $\mathrm{dS} \cdot \mathrm{m}^{-1}$ at $25^{\circ} \mathrm{C}$.

\section{Plant characteristics}

Yield and quality of the products were determined. For yield, the total weight was used as main characteristic. For fruit-vegetables the number of fruits and for flower crops the number of stalks were also determined. With respect to quality, attention was paid to disorders such as tipburn in lettuce and blossom-end rot in fruits, and to other defects such as uneven ripening of fruits.

\section{Statistical analysis}

Osmotic effects were analysed according to the pattern of Maas \& Hoffman (1977) (Fig. 1). Total weights of products from salinity treatments below the threshold value $(\mathrm{t})$ were fixed at $100 \%$. Weights from treatments with higher salinity were 


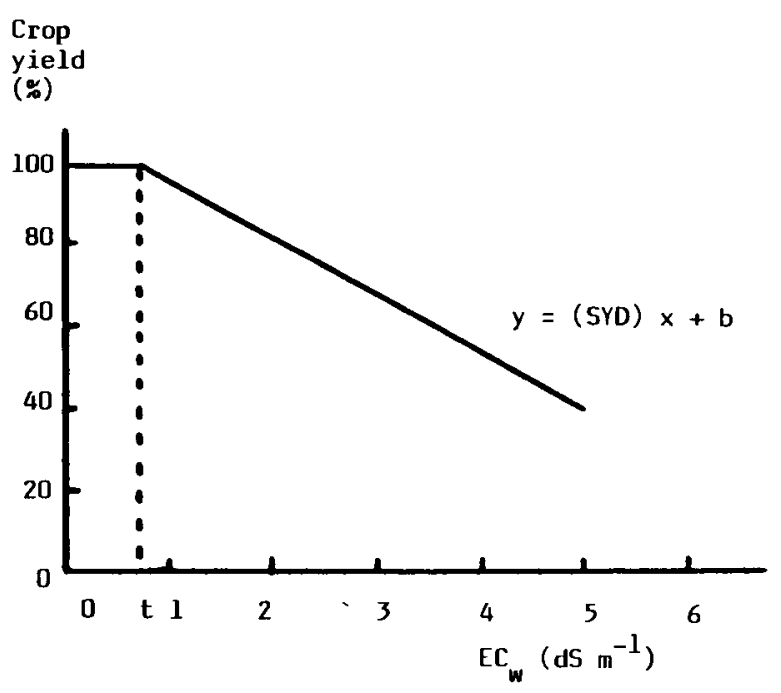

Fig. 1. Statistical analysis of crop yield data after the pattern of Maas \& Hoffman (1977). In the figure the threshold value (t) and the salinity yield decrease value (SYD) are shown.

expressed as percentages of weights below the threshold value. Salinity yield decrease (SYD) values were expressed as percentages per unit increase of the EC of the irrigation water, indicated by $\mathrm{EC}_{\mathrm{w}}$.

Relationships between EC values of irrigation water and those of saturation extract of soils were calculated to convert the one value into the other. Quality characteristics were usually expressed in percentages of affected plants or fruits. Some quality characteristics were rated by means of index figures.

Salinity effects can also be expressed in terms of osmotic pressure (OP). For the salt mixtures used in the experiments the expression OP (bar) $=0.33 \mathrm{EC}$ can be used to convert one value into the other. When specific salts were used, the OP was calculated and expressed as EC by using the same formula. So the osmotic effects of all experiments are expressed on an equal basis.

\section{Results}

Salinity yield decrease values

Salinity yield decrease (SYD) values for the different crops grown in the experiments are listed in Table 1. All effects found in the experiments A, C and D were significant. However, this was not the case for the results of experiment B. Only for lettuce and for tomatoes in the crop with the wider range of salt applications, significant yield reductions were found.

Apart from the relationships between $\mathrm{EC}_{\mathrm{w}}$ and yield for the experiments $\mathrm{A}$ and $\mathrm{C}$, relationships between $\mathrm{Cl}_{\mathrm{w}}$ and yield were calculated. In most cases the correlation coefficients for the relationships with $\mathrm{EC}_{\mathrm{w}}$ were higher. The few exceptions of 
Table 1. Salinity yield decrease values (SYD) as calculated from the results of the experiments.

\begin{tabular}{|c|c|c|c|c|c|}
\hline Crop & $\begin{array}{l}\text { Number of } \\
\text { croppings }\end{array}$ & $\begin{array}{l}\text { SYD } \\
(\%)\end{array}$ & Crop & $\begin{array}{l}\text { Number of } \\
\text { croppings }\end{array}$ & $\begin{array}{l}\text { SYD } \\
(\%)\end{array}$ \\
\hline
\end{tabular}

Experiment $A$

$\begin{array}{ll}\text { Spinach } & 2 \\ \text { Lettuce } & 5 \\ \text { Endive } & 1 \\ \text { Radish } & 1 \\ \text { Chrysanthemum } & 4 \\ \text { Tomato } & 3 \\ \text { Cucumber } & 2 \\ \text { Hot pepper } & 1 \\ \text { Bean } & 2 \\ \text { Sweet pepper } & 1\end{array}$

\section{Experiment $C$}

Carnation
cv. Scania
cv. Nora Barlo
Gerbera
cv. Mandarine
cv. Fabiola

Anthurium

cv. $A^{* *}$
cv. $B^{* *}$

Chrysanthemum

$$
\text { cv. Spider }
$$

cv. Horim

Hippeastrum cv. Diana cv. Red Lion

Alstroemeria cv. Pink Panther cv. Rosario
$+1.1$

3.9

4.7

5.2

5.6

7.3

14.8

15.1

17.6

18.3

Experiment $B$

Range $E C_{w} 0.1-1.5$

Tomato

Cucumber

Sweet pepper

Eggplant

Lettuce

Range $E C_{w} 0.1-2.8$

Tomato

1

Experiment $D$

6.9

5.5

12.0

19.7

$21.9^{* * *}$

$34.3^{* * *}$

6.8

12.1

19.0

16.3

14.7

15.4

* $\quad P>0.05$.

** Two newly selected, as yet unnamed cultivars.

*** Sodium chloride only $\left(1 \mathrm{dS} \cdot \mathrm{m}^{-1} \equiv 8.5 \mathrm{mmol} \mathrm{NaCl} \cdot 1^{-1}\right)$.

higher correlation coefficients for the relationships with $\mathrm{Cl}_{\mathrm{w}}$ show only small differences with the correlation coefficients for the relationships with $\mathrm{EC}_{\mathrm{w}}$. However, for one flower crop, namely anthurium, the difference was noteworthy. For this crop the SYD value in Table 1 was calculated on basis of $\mathrm{Cl}_{w}$.

Results of experiment D show that nearly all crops were specifically sensitive to sodium bicarbonate. This, however, was not a salinization effect but a sodicity effect. In a few cases, magnesium addition showed unfavourable specific effects on yields. Such effects were found with endive, cucumber and chrysanthemum. High 


\section{SONNEVELD}

calcium additions showed sometimes a favourable effect on yield. Such an effect was noticed for crops that are sensitive to calcium deficiency at high salinity, for example for lettuce and celery. Unfavourable effects of calcium were found with gerbera. High potassium additions were also unfavourable for this crop. Specific salinity effects in exp. D were not considered in the calculations of the SYD values.

The yield increase for spinach in experiment $\mathrm{A}$ is remarkable. This was probably caused by downy mildew (Peronospora farinosa f.sp. spinaciae); this fungus attacked the spinach especially at the low salinity, and lowered the yield at these treatments.

For nearly all crops the SYD values obtained in the different experiments show reasonable agreement. However, with chrysanthemum values between 5 and $16 \%$ were found. No satisfactory explanation is available for these large differences.

\section{Salinity threshold values}

Salinity threshold values ( $t$ values) are difficult to calculate, for reliable estimations require a large number of observations in the low salinity range. This was the case in experiment $B$ and more or less in experiment $C$.

In experiment B, two threshold values could be obtained for tomato and lettuce, as shown in Fig. 2. The threshold value for tomato was approximating $\mathrm{EC}_{\mathrm{w}}=1.8$. For lettuce a threshold value of approximately 0.7 was obtained. The other crops grown in this experiment did not show significant differences in the range up to $\mathrm{EC}_{\mathrm{w}}$ $=1.5$. It was therefore concluded that the threshold values will be higher.

In experiment $\mathrm{C}$, threshold values for most flower crops investigated were determined at a value of about $\mathrm{EC}_{\mathrm{w}}=0.6$. For carnation a value of about 1.0 was found.

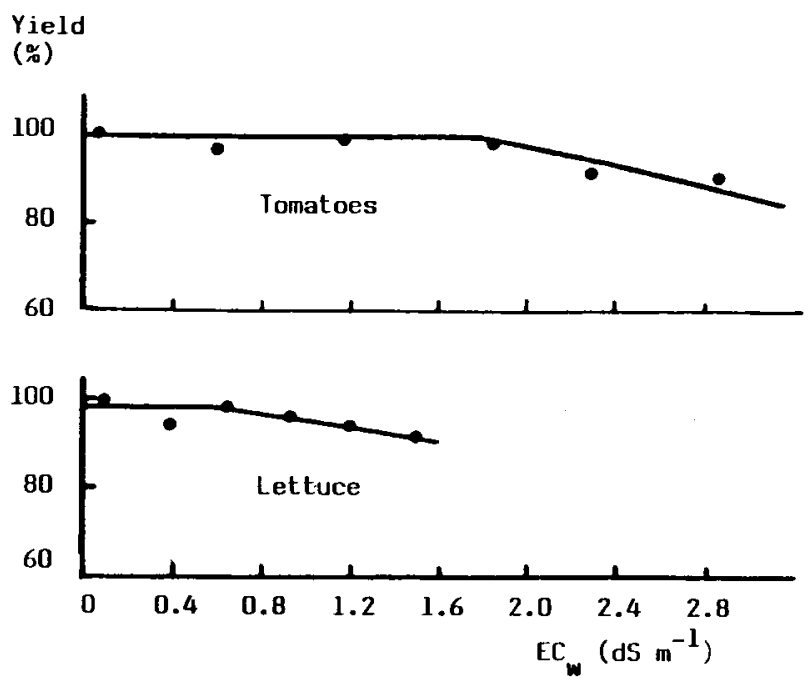

Fig. 2. The relationship between the EC of the irrigation water and the relative yield of tomatoes and lettuce. Results of experiment $B$. 


\section{Quality}

The product quality was sometimes influenced by the salinity. Positive as well as negative effects were found. Positive effects for example were a better fruit colour with tomato (see Table 2) and a higher resistance to fungus attack as described for spinach. The negative effects of salinity on quality are well-known and are often related to a low uptake rate of calcium, decreased xylem transport of this element or an unfavourable partitioning of cations in plant tissues. Examples of such effects are blossom-end rot of tomato and sweet pepper, blackheart of celery and tipburn

Table 2. The percentage of unevenly ripened tomato fruits as affected by the EC of the irrigation water. Experiment A.

\begin{tabular}{ll}
$\mathrm{EC}\left(\mathrm{dS} \cdot \mathrm{m}^{-1}\right)$ & Unevenly ripened fruits $(\%)$ \\
0.9 & 1.7 \\
1.8 & 0.5 \\
2.7 & 0.2 \\
3.6 & 0.0 \\
4.5 & 0.0 \\
\hline
\end{tabular}

Table 3. Percentages of sweet pepper fruits with blossom-end rot as affected by the EC of the irrigation water $\left(E C_{w}\right)$. Experiment $B$.

\begin{tabular}{ll}
$\overline{\mathrm{EC}}\left(\mathrm{ds} \cdot \mathrm{m}^{-1}\right)$ & Blossom-end rot $(\%)$ \\
0.1 & 0.24 \\
0.4 & 0.61 \\
0.6 & 0.65 \\
0.9 & 1.01 \\
1.2 & 0.91 \\
1.5 & 1.12 \\
\hline
\end{tabular}

Table 4. The effect of different cations on the appearance of blackheart of celery. Ion concentrations of 25 and $50 \mathrm{mmol}$ per liter irrigation water. Index: $0=$ no symptoms and $10=$ severe symptoms. Experiment D.

\begin{tabular}{lllll}
\hline Salts added & \multicolumn{2}{l}{ Index value for blackheart } \\
& 25 & 50 & 25 & 50 \\
& 5.0 & 2.0 & 9.6 & 9.6 \\
$\mathrm{NaCl}$ & 5.2 & 1.6 & 9.6 & 8.5 \\
$\mathrm{KCl}$ & 0.2 & 0.0 & 3.0 & 1.2 \\
$\mathrm{CaCl}_{2}$ & 5.8 & 2.3 & 9.8 & 8.9 \\
$\mathrm{MgCl}_{2}$ & & & & \\
\end{tabular}




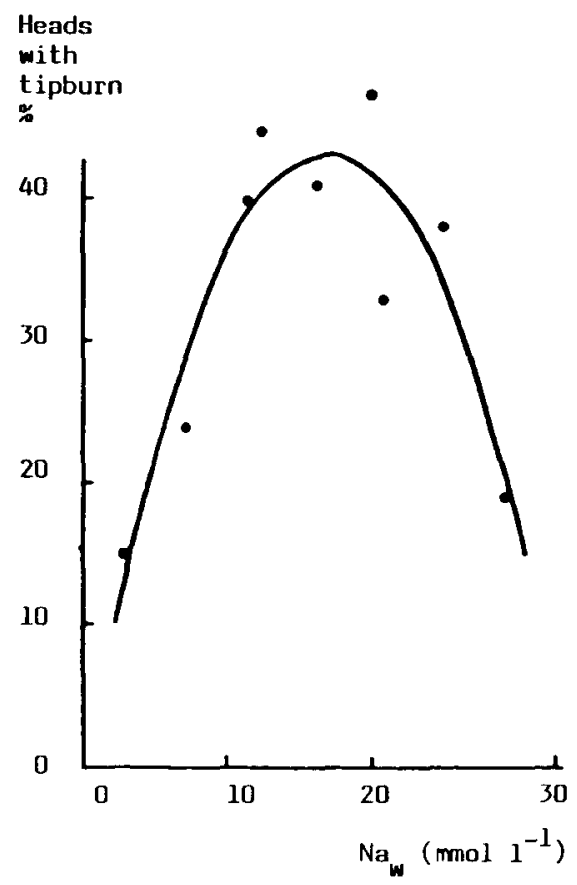

Fig. 3. The relationship between the sodium content of the irrigation water and the percentage of lettuce heads with tipburn. Results of a lettuce crop of experiment A. Function adjusted: $y=5.23 x-0.15$ $x^{2}-1.18, R=0.913$.

of lettuce. Some results of such effects found in the investigation are listed in Tables 3 and 4 and in Fig. 3.

However, calcium-related disorders are also affected by factors like growth rate and climatic conditions. The salinity effects on the disorders often show a strong interaction with such factors. For this reason it is difficult to quantify the salinity effects mentioned.

\section{Soil salinity}

Soil salinity was determined by a great number of samplings. It was closely correlated with the salt content of the irrigation water. The equations calculated for the relationship between $\mathrm{EC}_{\mathrm{w}}$ and $\mathrm{EC}_{\mathrm{c}}$ in the different experiments are listed in Table 5. The results of this table show that the salt accumulation factor between $E_{\mathrm{e}}$ and $\mathrm{EC}_{\mathrm{w}}$, reflected by the regression coefficients of the equations and the quotient $\Delta \mathrm{EC}_{\mathrm{e}} / \Delta \mathrm{EC}_{\mathrm{w}}$, for most of the experiments was around 1.5 . In experiment $\mathrm{B}$, however, the accumulation was much lower. The intercepts of the equations will be dependent mainly by the fertilization level. They tend to a value of $3 \mathrm{dS} \cdot \mathrm{m}^{-1}$. 


\section{Discussion}

The salinity yield decrease values for the irrigation water found for crops grown in greenhouse border soil (experiment A) are lower than those found for crops grown in basins (experiment D). An explanation for this observation will be the stronger salt accumulation in the basin soils as is apparent from Table 5.

There are differences in salt sensitivity between different cultivars of a crop, which is shown in the experiments with flower crops. Probably, the occasionally clear differences have to be explained by the accidental choice of the cultivars.

In Table 6, SYD values are compared with SYD values given by Maas \& Hoffman (1977) and by Maas (1985). For this purpose our SYD values for $\mathrm{EC}_{\mathrm{w}}$ were converted to $\mathrm{SYD}$ values for $\mathrm{EC}_{\mathrm{e}}$ by means of the equations listed in Table 8 , for Maas \& Hoffman (1977) expressed their SYD values on the basis of $E_{e}$.

The results of Table 6 show that on the whole the SYD values found by Maas \& Hoffman (1977) are higher than those found in our investigation. This is especially the case for lettuce, radish and spinach. The lower salt sensitivity may be explained

Table 5. Relationships between $\mathrm{EC}$ values of the irrigation water $\left(\mathrm{EC}_{\mathrm{w}}\right)$ and $\mathrm{EC}$ values of the saturation extracts of soils $\left(E C_{\mathrm{e}}\right)$.

\begin{tabular}{lll}
\hline Experiment & Number of samplings & Relationships \\
$\mathrm{A}$ & 16 & $\mathrm{EC}_{\mathrm{e}}=1.27 \mathrm{EC}_{\mathrm{w}}+2.62$ \\
$\mathrm{~B}$ & 20 & $\mathrm{EC}_{\mathrm{e}}=0.87 \mathrm{EC}_{\mathrm{w}}+3.15$ \\
$\mathrm{C}$ & 20 & $\mathrm{EC}_{\mathrm{e}}=1.33 \mathrm{EC}_{\mathrm{w}}+2.64$ \\
& 13 & $\frac{\Delta \mathrm{EC}_{\mathrm{e}}}{\Delta \mathrm{EC}_{\mathrm{w}}}=1.64$ \\
\hline
\end{tabular}

Table 6. Comparison of SYD values on basis of $E_{e}$ with SYD values given by Maas \& Hoffman (1977).

\begin{tabular}{|c|c|c|c|c|c|}
\hline \multirow[t]{3}{*}{ Crop } & \multicolumn{5}{|c|}{ SYD value (\%) } \\
\hline & \multicolumn{2}{|c|}{ on basis of $\mathrm{EC}_{\mathrm{w}}$} & \multicolumn{2}{|c|}{ on basis of $\mathrm{EC}_{\mathrm{e}}$} & \multirow[t]{2}{*}{ Maas \& Hoffman } \\
\hline & Exp. A & Exp. D & Exp. A & Exp. D & \\
\hline Bean & 17.6 & 24.1 & 13.9 & 14.7 & 19 \\
\hline Celery & - & 12.6 & - & 7.7 & 6.2 \\
\hline Cucumber & 14.8 & 14.5 & 11.7 & 8.8 & 13 \\
\hline Lettuce & 3.9 & 7.6 & 3.1 & 4.6 & 13 \\
\hline Pepper & 16.7 & 20.6 & 13.1 & 12.6 & 14 \\
\hline Radish & 5.2 & - & 4.1 & - & 13 \\
\hline Spinach & +1.1 & 1.9 & +0.9 & 1.2 & 7.6 \\
\hline Tomato & 7.3 & 10.7 & 5.7 & 6.5 & 9.9 \\
\hline
\end{tabular}


by the fact that our results were derived from experiments under glass in a rather humid sea climate, while the results reviewed by Maas \& Hoffman (1977) were derived for the greater part from experiments in the open in dry climates. Crops are more salt-sensitive when grown under dry climatic conditions than under humid conditions. The observation that the differences are largest for lettuce, radish, and spinach supports this explanation, for in our experiments those crops were grown in winter and early spring. Especially then the evaporative demand under glass is low in the Netherlands.

As already mentioned, the research data are not well suited to estimate salinity threshold values. The results of experiment $C$ showed threshold values for $E_{w}$ between 0.6 and 1.0. These values can be converted to $\mathrm{EC}_{\mathrm{e}}$ values of 3.4 and 4.0 , respectively. From experiment $\mathrm{B}$, threshold values were derived for $\mathrm{EC}_{\mathrm{w}}$ of 0.7 and 1.8. Conversion of these values to $\mathrm{EC}_{\mathrm{e}}$ shows values of 3.8 and 4.7. The data gathered by Maas \& Hoffman (1977) show threshold values for $\mathrm{EC}_{\mathrm{e}}$ between about 1.0 and 2.5. The difference between our values and those of Maas \& Hoffman can probably be explained, aside from the difference in climatic conditions, by differences in the watering regime of glasshouse crops. An intensive watering effectuates a constant high water content in the soil and so reduces the salinity effects.

Salinity can have both a positive and a negative effect on the quality of glasshouse produce. Positive effects are for example a better fruit colour of tomatoes as is indicated in Table 2. Other effects with tomatoes are for example higher contents of dry matter, sugar and acids (Gormley, 1984). This has a favourable influence on the taste of fruits. Furthermore for several greenhouse crops a somewhat high salinity level improves the keeping quality (Janse \& van Winden, 1985).

Negative effects of salinity on the quality of glasshouse produce are often related to calcium deficiency (Geraldson, 1979; Bernstein, 1964; Shear, 1975). In such cases the supply as well as the distribution of calcium may be affected by salinity. Also unfavourable uptake of cations and specific ion effects play a role in the appearance of calcium deficiency symptoms. This is indicated by the results for celery (Table 4) and lettuce (Fig. 3). The yield reductions caused by disorders like blackheart and tipburn are often much larger than those caused by the growth reduction. This was often the case with for example lettuce in our experiments. Fig. 3 shows that an addition of sodium chloride to the irrigation water equivalent to $1 \mathrm{dS} \cdot \mathrm{m}^{-1}$ $\left(8.5 \mathrm{mmol} \cdot \mathrm{l}^{-1}\right)$ increased the number of heads with tipburn with about $25 \%$. The growth reduction calculated for lettuce was about $5 \%$ per $\mathrm{dS} \cdot \mathrm{m}^{-1}$. The relationship between sodium chloride addition and tipburn in lettuce was not linear in all experiments. Sometimes with larger sodium chloride additions less tipburn was found. So quadratic relationships were found (Fig. 3). At high salinity, growth reduction becomes of importance and head formation is delayed. Reduced growth leads to relatively high calcium contents in the leaves; delayed head formation allows sustained transpiration of the younger leaves and hence calcium import in these leaves (Collier \& Huntington, 1983). In this way, both factors mentioned improve the calcium distribution and consequently prevent the occurrence of tipburn. 


\section{References}

Bernstein, L., 1964. Effects of salinity on mineral composition and growth of plants. In: C. Bould, P. Prevot and J. R. Magness (Eds), Plant Analysis and Fertilizer Problems, p. 25-45. Proceedings of the 4th International Colloquium, Brussels, Belgium, W. E. Humphrey Press Inc., Geneva, New York 4.

Collier, G. F. \& V. C. Huntington, 1983. The relationship between leaf growth calcium accumulation and distribution, and tipburn development in field-grown butterhead lettuce. Scientia Horticulturae 21: $123-128$.

Geraldson, C. M., 1979. Minimal calcium stress using the gradient mulch production system. Communications in Soil Science and Plant Analysis 10: 163-169.

Gormley, T. R. 1984. Organoleptic and nutritional quality of tomato fruit cultivars grown under intensive systems, 1981-83. Report SCAR Agro Food Programme, Contract 1081. Kinsealy Research Centre, Dublin, $49 \mathrm{pp}$.

Janse, J. \& C. M. M. van Winden, 1985. Quality and chemical composition of tomatoes grown on rockwool. In: T. R. Gormley, R. O. Sharples and J. Dehandtschutter (Eds), The Effects of Modern Production Methods on the Quality of Tomatoes and Apples, p. 93-102. Commission of the European Communities, Luxembourg.

Maas, E. V. \& G. J. Hoffman, 1977. Crop salt tolerance - Current assessment. Journal of the Irrigation and Drainage Division, Proceedings of the American Society of Civil Engineers 103 (IR2): 115-134.

Maas, E. V., 1985. Crop tolerance to saline sprinkling water. Plant and Soil 89: 273-284.

Shear, C. B., 1975. Calcium-related disorders of fruits and vegetables. HortScience 10: 361-365.

Sonneveld, C. \& J. van den Ende, 1971. Soil analysis by means of a 1:2 volume extract. Plant and Soil 35: 505-516.

Sonneveld, C. \& J. van Beusekom, 1972. The effects of saline irrigation water on some vegetables under glass. Acta Horticulturae 35: 75-85.

Sonneveld, C. \& J. van den Ende, 1975. The effect of some salts on head weight and tipburn of lettuce and on fruit production and blossom-end rot of tomatoes. Netherlands Journal of Agricultural Science 23: 191-201.

Sonneveld, C. \& S. J. Voogt, 1978. Effects of saline irrigation water on glasshouse cucumbers. Plant and Soil 49: 595-606.

Sonneveld, C., 1979. Effects of salinity on the growth and mineral composition of sweet pepper and eggplant grown under glass. Acta Horticulturae 89: 71-78.

Sonneveld, C. \& W. Voogt, 1983. Studies on the salt tolerance of some flower crops grown under glass. Plant and Soil 74: 41-52.. 